\title{
Syndrome de Brugada
}

\section{Brugada's syndrome}

\section{P. Taboulet}

Reçu le 8 octobre 2010 ; accepté le 9 novembre 2010

(C) SFMU et Springer-Verlag France 2011

Un patient de 25 ans, étudiant en cinématographie, consulte aux urgences pour malaises à répétition, le dernier étant syncopal. Ces malaises surviennent principalement lorsqu'il visualise des films au repos dans l'obscurité. Son ECG révèle un aspect caractéristique du syndrome de Brugada (ou ECG Brugada type 1) : ascension du point J supérieure ou égale à $0,2 \mathrm{mV}$ avec sus-décalage du segment $\mathrm{ST}$ graduellement descendant, sur plus d'une dérivation précordiale droite (V1-V3), avec un aspect en dôme et une onde T inversée [1]. Le terme « syndrome de Brugada » est réservé à l'association d'un ECG type 1 avec au moins un des critères suivants : fibrillation ventriculaire, tachycardie ventriculaire polymorphe, syncope ou respiration nocturne agonique, TV induite, histoire familiale de syncope $(<45$ ans) ou ECG de type 1 dans la famille [1].

\section{Référence}

1. Antzelevitch C, Brugada P, Borggrefe M, et al (2005) Brugada syndrome. Report of the second consensus conference. Endorsed by the Heart Rhythm Society and the European Heart Rhythm Association. Circulation 111:659-70

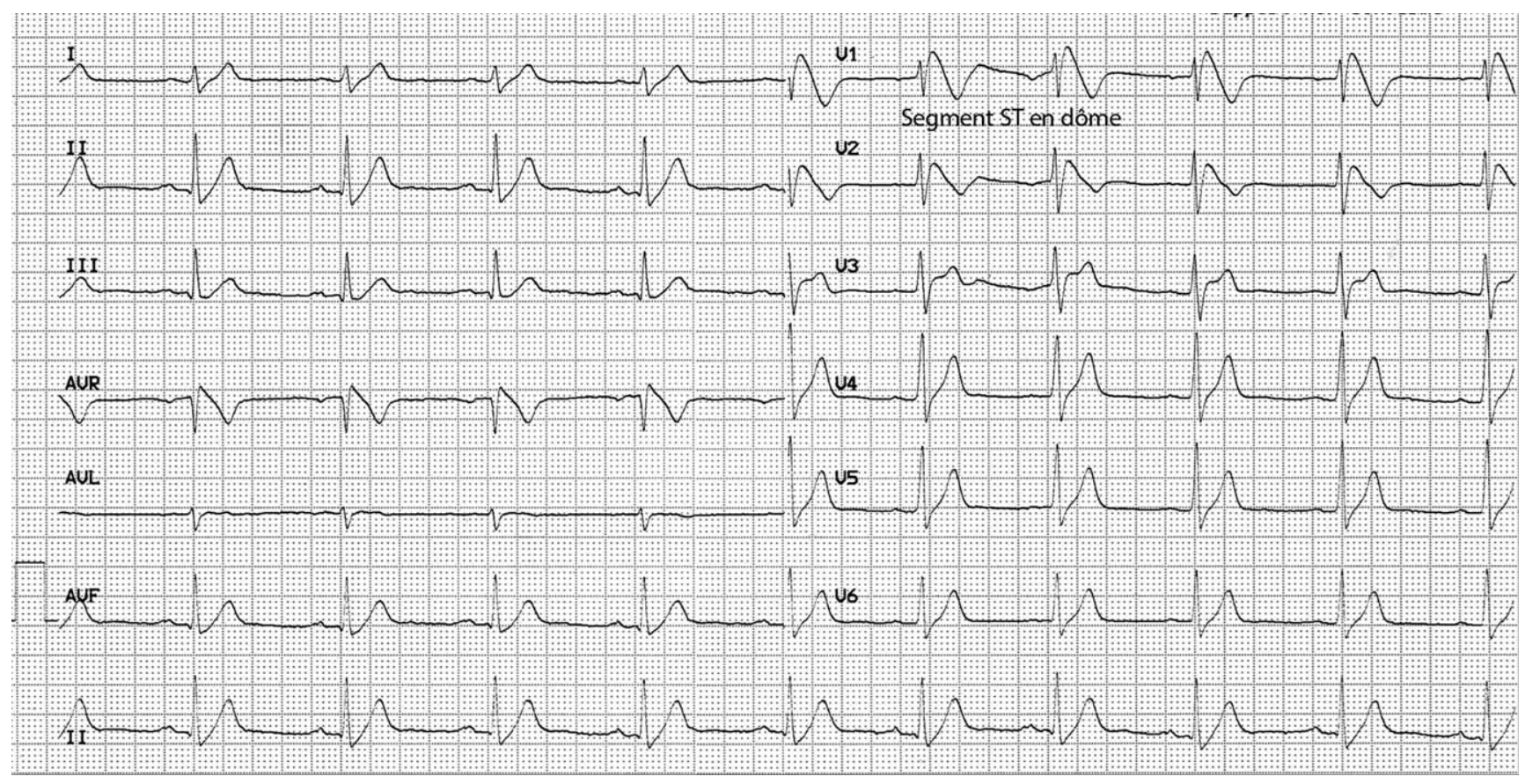

P. Taboulet $(\bowtie)$

Service des urgences, hôpital Saint-Louis,

Assistance-publique-Hôpitaux de Paris, F-75010 Paris,

France

e-mail : pierre.taboulet@sls.aphp.fr 